\title{
Common occurrence of divergent Cryptosporidium species and Cryptosporidium parvum subtypes in farmed bamboo rats (Rhizomys sinensis)
}

Falei Li ${ }^{1,2}$, Zhenjie Zhang ${ }^{1}$, Suhui Hu${ }^{1}$, Wentao Zhao ${ }^{1}$, Jianguo Zhao ${ }^{3}$, Martin Kváč ${ }^{4}$, Yaqiong Guo ${ }^{1}$, Na Li ${ }^{1}$, Yaoyu Feng ${ }^{1,2^{*}}$ and Lihua Xiao ${ }^{1,2^{*}}$ (D)

\begin{abstract}
Background: Bamboo rats are widely farmed in southern China for meat, but their potential in transmitting pathogens to humans and other farm animals remains unclear.

Methods: To understand the transmission of Cryptosporidium spp. in these animals, 709 fecal samples were collected in this study from Chinese bamboo rats (Rhizomys sinensis) on nine farms in Jiangxi, Guangxi and Hainan provinces, China. They were analyzed for Cryptosporidium spp. using PCR and sequence analyses of the small subunit rRNA gene. Cryptosporidium parvum, C. parvum-like and C. ubiquitum-like genotypes identified were subtyped by sequence analysis of the $60 \mathrm{kDa}$ glycoprotein (gp60) gene.

Results: Altogether, Cryptosporidium spp. were detected in 209 (29.5\%) samples. The detection rate in samples from animals under two months of age $(70.0 \%, 105 / 150)$ was significantly higher than in samples from animals above 2 months $\left(18.6 \%, 104 / 559 ; x^{2}=150.27, d f=1, P<0.0001\right)$. Four Cryptosporidium species/genotypes were identified: $C$. parvum ( $n=78)$; C. occultus $(n=1)$; a new genotype that is genetically related to C. ubiquitum $(n=85)$; and another new genotype that is genetically related to C. parvum ( $n=44)$. Among them, C. parvum $(27,610 \pm 71,911$ oocysts/ gram of feces) and the C. parvum-like genotype (38,679 $\pm 82,811$ oocysts/gram of feces) had higher oocyst shedding intensity than the C. ubiquitum-like genotype (2470 \pm 7017 oocysts/gram of feces) and the C. occultus (1012 oocysts/ gram of feces). The C. parvum identified belonged to three subtypes in two rare subtype families, including IIpA9 $(n=43)$, IIPA6 $(n=6)$ and IIoA15G1 $(n=9)$, while the C. parvum-like and C. ubiquitum-like genotypes generated very divergent gp60 sequences.

Conclusions: Results of the present study suggest that bamboo rats on the study farms were infected with diverse Cryptosporidium species and divergent C. parvum subtypes, which probably had originated from their native habitats. As similar C. parvum subtypes have been recently detected in humans and farmed macaques, attentions should be paid to the potential role of these new farm animals in the transmission of zoonotic pathogens.
\end{abstract}

Keywords: Cryptosporidium, Zoonotic, Bamboo rat, Subtype, Molecular epidemiology

\footnotetext{
*Correspondence: yyfeng@scau.edu.cn; Ixiao1961@gmail.com

${ }^{1}$ Key Laboratory of Zoonosis of Ministry of Agriculture, College

of Veterinary Medicine, South China Agricultural University,

Guangzhou 510642, Guangdong, China

Full list of author information is available at the end of the article
}

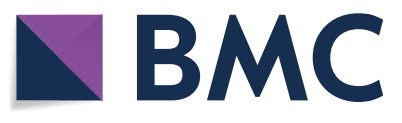

(c) The Author(s) 2020. This article is licensed under a Creative Commons Attribution 4.0 International License, which permits use, sharing, adaptation, distribution and reproduction in any medium or format, as long as you give appropriate credit to the original author(s) and the source, provide a link to the Creative Commons licence, and indicate if changes were made. The images or other third party material in this article are included in the article's Creative Commons licence, unless indicated otherwise in a credit line to the material. If material is not included in the article's Creative Commons licence and your intended use is not permitted by statutory regulation or exceeds the permitted use, you will need to obtain permission directly from the copyright holder. To view a copy of this licence, visit http://creativeco mmons.org/licenses/by/4.0/. The Creative Commons Public Domain Dedication waiver (http://creativecommons.org/publicdomain/ zero/1.0/) applies to the data made available in this article, unless otherwise stated in a credit line to the data. 


\section{Background}

Cryptosporidium spp. are protozoan parasites inhabiting the gastrointestinal epithelium of humans and other vertebrate animals [1]. They are ubiquitous in the environment; humans can be infected with Cryptosporidium spp. through contact with infected persons (anthroponotic transmission) or animals (zoonotic transmission) and ingestion of contaminated food (food-borne transmission) or water (water-borne transmission) [2].

To date, over 40 Cryptosporidium species have been recognized, together with almost an equal number of genotypes [3]. Among them, Cryptosporidium parvum has a broad host range and is the major Cryptosporidium species associated with the occurrence of diarrhea in farm animals [4]. As one of the two dominant Cryptosporidium species in humans, it is an important zoonotic pathogen [2]. Sequence analysis of the $60 \mathrm{kDa}$ glycoprotein $(g p 60)$ gene has identified over 20 subtype families of $C$. parvum [5]. Among them, the common ones are host-adapted, such as IIa in dairy cattle, IIc in humans, and IId in small ruminants [3]. Others, such as the newly identified subtype families IIp and IIo, were found mainly in bamboo rats and crab-eating macaques $[6,7]$. Cryptosporidium ubiquitum is another zoonotic species with a broad host range. Sequence analysis of the gp60 gene has also identified host-adapted subtype families within the species, some of which have been found in humans and small ruminants in industrialized nations, while others have been found in rodents [8]. Therefore, genetic characterization is important in the assessment of the pathogenicity and public health potential of Cryptosporidium spp. in animals.

Bamboo rats are widely farmed in China since 1990 due to the high protein content and perceived medical values of the meat [9]. There were about 10,000 farms (households) of bamboo rats in China in 2011, with an annual production of 30 million animals, of which $\sim 500,000$ were exported to Southeast Asian countries [10]. However, in China, bamboo rats have long been known as a reservoir of the opportunistic pathogen Penicillium marneffei $[11,12]$. In recent years, other emerging pathogens such as Akabane virus, beta-lactam resistant Escherichia coli, Enterocytozoon bieneusi and Giardia duodenalis have been detected in farmed bamboo rats [9, 13-15]. In a study of 92 fecal samples collected from a pet market in Sichuan Province, those from one asymptomatic and two diarrheic bamboo rats were positive for $C$. parvum [6]. Therefore, as recently domesticated rodents, bamboo rats have the potential of transmitting zoonotic pathogens to other farm animals and humans.

In this study, we examined the occurrence of Cryptosporidium spp. in farmed bamboo rats in southern China and identified the presence of diverse Cryptosporidium species and divergent $C$. parvum subtypes in these animals. We postulate that these unusual Cryptosporidium spp. probably originated from their native habitats.

\section{Methods \\ Specimens}

Between September 2017 and December 2018, 709 fecal samples were collected from Chinese bamboo rats (Rhizomys sinensis) on nine farms in Jiangxi, Guangxi, and Hainan provinces, China. Most of the farms sampled were newly established with predominantly adult animals and a small number of young animals. In contrast, Farms 1 and 4 were established facilities, had over 1000 bamboo rats per farm, and provided animals to other farmers because of the availability of large numbers of young animals. On these farms, 5-10 bamboo rats were kept in the same pen, except for breeding pairs, which were kept in individual pens. For young animals under 6 months of age, 2-4 samples of fresh fecal pellets were collected from different locations in the pen to minimize repeated sampling of the same animal, while for older animals, only one sample was collected per pen. The animals in the study were divided into 6 convenient age groups: 1-2 months-old; 3-4 months-old; 5-6 months-old; 7-9 months-old; and 1-3 years-old; with a few of unknown age (Table 1). These fecal samples were stored in $2.5 \%$ potassium dichromate before DNA extraction.

\section{Detection, genotyping and subtyping of Cryptosporidium spp.}

Aliquots of $200 \mathrm{mg}$ fecal samples were washed to remove potassium dichromate with distilled water by centrifugation at $2000 \times g$ for $10 \mathrm{~min}$. DNA was extracted from washed fecal materials using the Fast DNA Spin Kit for Soil (MP Biomedical, Santa Ana, CA, USA) as previously described [16]. The extracted DNA was analyzed for Cryptosporidium spp. using a nested PCR targeting a 830-bp fragment of the small subunit rRNA (SSU rRNA) gene [17]. Representative Cryptosporidium species/genotypes were characterized by restriction fragment length polymorphism (RFLP) analysis of the secondary SSU rRNA PCR products using restriction enzymes SspI (New England BioLabs, Massachusetts, USA) and VspI (Promega, Madison, WI, USA) [17]. The C. parvum, C. parvum-like genotype and C. ubiquitumlike genotype identified in this study were further subtyped by PCR and sequence analysis of the gp60 gene $[18,19]$. The intensity of oocyst shedding was assessed by using a SYBR Green-based qPCR (18S-LC2) targeting a $\sim 278$-bp fragment of the SSU rRNA gene [20]. The master mix of the qPCR contained $10 \mu \mathrm{l}$ of $2 \times$ SYBR Green real-time PCR master mix (Thermo Fisher Scientific, Waltham, MA, USA) in a $20 \mu$ reaction. The qPCR 
Table 1 Distribution of Cryptosporidium species/genotypes and Cryptosporidium parvum subtypes in bamboo rats on farms in Jiangxi, Hainan and Guangxi provinces, China

\begin{tabular}{|c|c|c|c|c|c|c|c|c|c|}
\hline \multirow[t]{2}{*}{ Location } & \multirow[t]{2}{*}{ Farm } & \multirow[t]{2}{*}{ Animal age } & \multirow[t]{2}{*}{$n$} & \multirow[t]{2}{*}{ No. positive (\%) } & \multicolumn{5}{|c|}{ Cryptosporidium spp. } \\
\hline & & & & & $\begin{array}{l}\text { C. } \\
\text { ubiquitum- } \\
\text { like }\end{array}$ & C. parvum-like & C. occultus & C. parvum & C. parvum subtype \\
\hline \multirow[t]{20}{*}{ Guangxi } & \multirow[t]{4}{*}{1} & 0-2 months & 9 & $7(77.8)$ & 4 & 3 & - & - & - \\
\hline & & 7-9 months & 6 & $2(33.3)$ & 2 & - & - & - & - \\
\hline & & $1-3$ years & 88 & $16(18.2)$ & 5 & 4 & - & 7 & IIoA15G1 $(n=6)$ \\
\hline & & Subtotal & 103 & $25(24.3)$ & 11 & 7 & - & 7 & IIoA15G1 $(n=6)$ \\
\hline & \multirow[t]{3}{*}{2} & 0-2 months & 11 & $2(18.2)$ & 1 & - & - & 1 & $\| p A 6(n=1)$ \\
\hline & & $1-3$ years & 43 & $1(2.3)$ & - & - & - & 1 & - \\
\hline & & Subtotal & 54 & $3(5.6)$ & 1 & - & - & 2 & $\| p A 6(n=1)$ \\
\hline & \multirow[t]{3}{*}{3} & 0-2 months & 4 & $1(25.0)$ & - & - & - & 1 & $\| p A 6(n=1)$ \\
\hline & & $1-3$ years & 24 & $2(8.3)$ & 2 & - & - & - & - \\
\hline & & Subtotal & 28 & $3(10.7)$ & 2 & - & - & 1 & $\| p A 6(n=1)$ \\
\hline & \multirow[t]{6}{*}{4} & 0-2 months & 50 & $34(68.0)$ & 2 & 21 & - & 11 & $\| p A 9(n=7)$ \\
\hline & & 3-4 months & 25 & $12(48.0)$ & 10 & & - & 2 & $\operatorname{\| pA9}(n=1)$ \\
\hline & & 4-6 months & 28 & $11(39.3)$ & 8 & 3 & - & - & - \\
\hline & & 7-9 months & 16 & $5(31.3)$ & 2 & 2 & - & 1 & - \\
\hline & & $1-3$ years & 123 & $6(4.9)$ & 4 & 1 & - & 1 & $\| p A 9(n=1)$ \\
\hline & & Subtotal & 244 & $68(27.9)$ & 26 & 28 & - & 14 & $\| p A 9(n=9)$ \\
\hline & \multirow[t]{2}{*}{5} & 1-3 years & 30 & $2(6.7)$ & 1 & - & - & 1 & - \\
\hline & & Subtotal & 30 & $2(6.7)$ & 1 & - & - & 1 & - \\
\hline & \multirow[t]{2}{*}{6} & $1-3$ years & 18 & $2(11.1)$ & - & 1 & - & 1 & - \\
\hline & & Subtotal & 18 & $2(11.1)$ & - & 1 & - & 1 & - \\
\hline \multirow[t]{6}{*}{ Jiangxi } & \multirow[t]{6}{*}{7} & 0-2 months & 18 & $15(83.3)$ & 9 & - & - & 6 & $\|p A 9(n=3)\| p A ,6(n=3)$ \\
\hline & & 3-4 months & 19 & $10(52.6)$ & 8 & - & 1 & 1 & $\| p A 9(n=1)$ \\
\hline & & 4-6 months & 21 & $7(33.3)$ & 6 & - & - & 1 & $\| p A 9(n=1)$ \\
\hline & & 7-9 months & 13 & $3(23.1)$ & 3 & - & - & - & - \\
\hline & & $1-3$ years & 82 & $16(19.5)$ & 12 & - & - & 4 & $\operatorname{\| pA9}(n=4)$ \\
\hline & & Subtotal & 153 & $51(33.3)$ & 38 & - & 1 & 12 & $\|p A 9(n=9)\| p A ,6(n=3)$ \\
\hline \multirow[t]{7}{*}{ Hainan } & \multirow[t]{4}{*}{8} & $0-2$ months & 17 & $13(76.5)$ & 5 & 4 & & 4 & $\|\operatorname{pA}(n=1),\| \circ A 15 G 1(n=2)$ \\
\hline & & 3-4 months & 6 & $5(83.3)$ & - & 4 & - & 1 & IIoA15G1 $(n=1)$ \\
\hline & & 4-6 months & 3 & $2(66.7)$ & - & 1 & - & 1 & - \\
\hline & & Subtotal & 26 & $20(76.9)$ & 5 & 9 & - & 6 & $\|\mathrm{pA} 6(n=1),\| \mathrm{oA} 15 \mathrm{G} 1(n=3)$ \\
\hline & \multirow[t]{3}{*}{9} & 0-2 months & 41 & $34(82.9)$ & - & - & - & 34 & $\| p A 9(n=25)$ \\
\hline & & Unknown & 12 & $1(8.3)$ & 1 & - & - & - & - \\
\hline & & Subtotal & 53 & $35(66.0)$ & 1 & - & - & 34 & $\| p A 9(n=25)$ \\
\hline Total & & - & 709 & $209(29.4)$ & 85 & 45 & 1 & 78 & $\begin{array}{l}\|\circ A 15 G 1(n=9),\| p A 9(n= \\
43), \| p A 6(n=6)\end{array}$ \\
\hline
\end{tabular}

was performed on a LightCycler 480 II (Roche, Indianapolis, IN, USA) as described previously [7]. All qPCR analyses included one positive control and two negative controls. The number of oocysts per gram of feces (opg) was calculated based on the $\mathrm{Cq}$ values of the amplification obtained from the analyzed sample against a standard curve generated from qPCR analysis of fecal samples spiked with known numbers of oocysts of the C. parvum IOWA isolate (Waterborne, Inc., New Orleans, USA).

\section{Sequence analysis}

All positive PCR products of the SSU rRNA and gp60 genes were sequenced bi-directionally on an ABI 3730 Autosequencer (Applied Biosystems, Foster City, CA, USA) to identify the Cryptosporidium species and $C$. parvum subtypes presented, respectively. The nucleotide sequences generated were assembled using ChromasPro 2.1.5.0 (http://technelysium.com.au/ChromasPro.html), edited using BioEdit 7.1.3.0 (http://www.mbio.ncsu. 
Table 2 Occurrence of Cryptosporidium species/genotypes in farmed bamboo rats in Guangxi, Jiangxi and Hainan provinces, China, broken down by age

\begin{tabular}{|c|c|c|c|c|c|c|c|}
\hline \multirow[t]{2}{*}{ Age } & \multirow[t]{2}{*}{$n$} & \multirow[t]{2}{*}{ No. positive (\%) } & \multicolumn{4}{|c|}{ Cryptosporidium spp. } & \multirow[t]{2}{*}{ C. parvum subtype } \\
\hline & & & $\begin{array}{l}\text { C. ubiquitum- } \\
\text { like }\end{array}$ & C.parvum-like & C. occultus & C.parvum & \\
\hline $0-2$ months & 150 & $105(70.0)$ & 21 & 28 & 0 & 56 & $\|p A 9(n=36)\| p A ,6(n=6)$ \\
\hline $3-4$ months & 50 & $28(56.0)$ & 18 & 5 & 1 & 4 & $\|$ pA9 $(n=2), \| o A 15 G 1(n=2)$ \\
\hline $4-6$ months & 53 & $20(37.7)$ & 14 & 4 & 0 & 2 & $\|\mathrm{pA} 9(n=1),\| \mathrm{oA} 15 \mathrm{G} 1(n=1)$ \\
\hline 7-9 months & 36 & $10(27.8)$ & 7 & 2 & 0 & 1 & - \\
\hline $1-3$ years & 408 & $45(11.0)$ & 24 & 6 & 0 & 15 & $\|\mathrm{pA} 9(n=4),\| \mathrm{oA} 15 \mathrm{G} 1(n=6)$ \\
\hline Unknown & 12 & $1(8.3)$ & 1 & 0 & 0 & 0 & - \\
\hline Total & 709 & $209(29.5)$ & 85 & 45 & 1 & 78 & $\begin{array}{l}\|p A 9(n=43),\| p A 6(n=6) \\
\| \text { IoA15G1 }(n=9)\end{array}$ \\
\hline
\end{tabular}

Abbreviations: $\mathrm{n}$, total number of samples; -, gp60 PCR negative

edu/BioEdit/bioedit.html), and aligned with reference sequences from GenBank using ClustalX 2.0.11 (http:// clustal.org). The maximum likelihood analysis implemented in Mega 6.0 (http://www.megasoftware.net) was used to assess the phylogenetic relationship of the novel Cryptosporidium genotypes to other Cryptosporidium species and genotypes. The general time reversible model was used in the phylogenetic analysis, with the robustness of clade formation being assessed using bootstrap analysis with 1000 replicates. Representative nucleotide sequences generated in this study were submitted to the GenBank database under accession the numbers MK956928MK956937, MK955996-MK956002, MT019967 and MT019968.

\section{Statistical analysis}

Cryptosporidium detection rates in bamboo rats were compared among age and reproduction groups using the Chi-square test implemented in SPSS v.20.0 (IBM Corp., New York, NY, USA). Differences were considered significant at $P<0.05$.

\section{Results}

\section{Cryptosporidium infection in bamboo rats}

Of the 709 samples collected from bamboo rats on 9 farms, 209 (29.5\%) were positive for Cryptosporidium spp. in PCR analysis of the SSU rRNA gene. The detection rates in bamboo rats ranged from 5.6\% to 76.9\% among the 9 farms (Table 1). Farms 8 and 9 in Hainan had significantly higher detection rates than other farms $\left(x^{2}=17.6, d f=1, \quad P<0.0001 ; \chi^{2}=17.3\right.$, $d f=1, P<0.0001$; respectively). Among the 6 farms in Guangxi, Farms 1 and 4 had slightly higher detection rates than other farms $\left(\chi^{2}=0.866, d f=1, P=0.22\right.$; $X^{2}=1.62, d f=1, P=0.121$; respectively). Regarding rat age, the highest detection rate was $70.0 \%$ in the 0-2 month-old group, which was significantly higher than in older animals overall $\left(18.6 \% ; \chi^{2}=165.2, d f=1\right.$, $P<0.0001)$, especially in $1-3$ year-old animals $(11.0 \%$; $X^{2}=194.1, P<0.0001$; Table 2).

\section{Cryptosporidium species/genotypes}

All 209 Cryptosporidium-positive PCR products of the $S S U$ rRNA gene were successfully sequenced. The results showed the presence of C. parvum $(n=78)$, Cryptosporidium occultus $(n=1)$, and two new Cryptosporidium genotypes. Of the latter, one was genetically related to $C$. ubiquitum $(n=85)$, while the other was related to C. parvum $(n=44)$. The nucleotide sequences generated from C. parvum were identical to each other and a nucleotide sequence (GenBank: KC885892) also obtained from bamboo rats [6]. The latter had one A to $\mathrm{T}$ substitution from the SSU rRNA sequences of C. parvum commonly found in humans, cattle and other animals (Fig. 1). Similarly, the nucleotide sequence from $C$. occultus had two nucleotide substitutions compared with the GenBank sequence MH807493 obtained from humans. The C. ubiquitumlike genotype had 17 nucleotide substitutions compared with the partial SSU rRNA gene sequence obtained previously from C. ubiquitum (GenBank: KY596691) in Chinchilla lanigera [21], while the C. parvum-like genotype had 11 nucleotide differences from a partial SSU rRNA gene sequence of C. parvum reported from dairy cattle (GenBank: MF074700) [22]. As expected, in the phylogenetic analysis of the $S S U$ rRNA nucleotide sequences, the C. parvum-like genotype clustered together with C. parvum, while the C. ubiquitum-like genotype clustered with C. ubiquitum (Fig. 2).

The Cryptosporidium species and genotypes identified in the present study produced different banding patterns in a RFLP analysis of the $S S U$ rRNA PCR products using 


\begin{tabular}{|c|c|c|c|c|c|c|c|}
\hline & 430 & 440 & 450 & 460 & 470 & 480 & 490 \\
\hline C. parvum AF093493 & TAATAATTT- & ATATAAAATA & TTTTGATGAA & TATTTATATA & АTATTAACAT & AATTCATATT & АСТАТАТАТ- \\
\hline C. parvum AY268582 & $\ldots-$ & $\cdots$ & $\cdots$ & $\cdots \cdots$ & $\ldots$ & $\ldots$ & $\ldots \ldots \ldots$ \\
\hline C. parvum KC885892 & $\ldots \ldots \ldots-$ & $\ldots$ & $\ldots$ & $\ldots$ & $\ldots$ & $\ldots$ & ...т.- \\
\hline 11021 C. parvum & $\ldots \ldots \ldots-$ & $\ldots$ & $\ldots \ldots \ldots$ & $\ldots \ldots \ldots$ & $\ldots$ & $\ldots$ & $\ldots \ldots$ T. - \\
\hline 11117 C. parvum & $\ldots \ldots \ldots-$ & $\ldots$ & $\ldots$ & $\ldots$ & $\ldots$ & $\ldots$ & 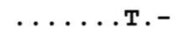 \\
\hline 10771 C. parvum & $\ldots \ldots \ldots-$ & $\ldots \ldots \ldots$ & $\ldots \ldots \ldots$ & $\ldots \ldots \ldots$ & $\ldots \ldots$ & $\ldots \ldots \ldots$ & $\ldots \ldots$ т. - \\
\hline 10741 C. parvum-like & $\ldots \ldots \ldots-$ & $\ldots \ldots \ldots$ & $\ldots-\ldots$ т. & $\ldots \ldots \ldots$ & $\ldots \ldots \ldots$ & $\ldots$ & …T. - \\
\hline 10748 C. parvum-like & $\ldots \ldots \ldots-$ & $\ldots \ldots \ldots$ & $\ldots-\ldots$. & $\ldots \ldots \ldots \ldots$ & $\ldots \ldots \ldots$ & $\ldots \ldots \ldots$ & 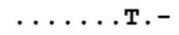 \\
\hline C. ubiquitum MK573335 & $\ldots \ldots \ldots-$ & $\ldots \ldots$ т. & . .АТ. $-\ldots$ & $\ldots \ldots \ldots$ & G. . . W & $\ldots \ldots \ldots$ & 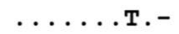 \\
\hline C. ubiquitum KY596694 & $\ldots \ldots \ldots-$ & $\ldots \ldots$ т... & ...АТ. $-\ldots$ & $\ldots \ldots \ldots$ & $\ldots$. & $\ldots \ldots \ldots$ & ….. \\
\hline C. ubiquitum KY596691 & $\ldots$ & $\ldots \ldots$ т. & ...АT. $-\ldots$ & $\ldots$ & G... & $\cdots$ & $\ldots \ldots$ T. - \\
\hline 11051 C. ubiquitum-like & $\ldots \ldots \ldots \mathrm{T}$ & $\ldots$. c... & $\ldots$. . $-\ldots$ & $\ldots \ldots \ldots$ & G... & $\ldots$ & $\ldots$ G...A \\
\hline 11098 c. ubiquitum-like & $\ldots \ldots \ldots$ т & $\ldots$. с . & $\ldots$ A. $-\ldots$ & $\ldots \ldots \ldots$ & $G \ldots \ldots \ldots$ & $\ldots \ldots$ & $\ldots$ G...A \\
\hline C. suis MH8077493 & $\ldots \ldots$ & $\ldots \ldots$. . . & $\ldots$. A. -G- & $\ldots \ldots \ldots$ & $\ldots$ & $\ldots$ & $\ldots$. \\
\hline 5019 C. occultus & $\ldots \ldots \ldots-$ & $\ldots$. . . . & ...A. -G- & & & & .T.C- \\
\hline & 500 & 510 & 520 & 530 & 540 & 550 & 560 \\
\hline C. parvum AF093493 & ---TTTAGTA & TATGAAATTT & TACTTTGAGA & AAATTAGAGT & GCTTAAAGCA & GGCATAT--G & ССTT-GAATA \\
\hline C. parvum AY268582 & $---\ldots \ldots$ & $\ldots \ldots \ldots$ & $\ldots \ldots \ldots$ & $\ldots \ldots \ldots$ & $\ldots \ldots \ldots$ & $\ldots \ldots--$ & $\ldots-\ldots$ \\
\hline C. parvum KC885892 & $---\ldots \ldots$ & $\ldots \ldots \ldots$ & $\ldots \ldots \ldots$ & $\ldots \ldots \ldots$ & $\ldots \ldots \ldots$ & $\ldots \ldots{ }^{--}$ & $\ldots-\ldots \ldots$ \\
\hline 11021 C. parvum & $--\ldots \ldots$ & $\ldots \ldots \ldots$ & $\ldots \ldots \ldots$ & $\ldots \ldots \ldots$ & $\ldots \ldots \ldots$ & $\ldots \ldots--$ & $\ldots-\ldots$ \\
\hline 11117 C. parvum & $---\ldots \ldots$ & $\ldots \ldots \ldots$ & $\ldots \ldots \ldots$ & $\ldots \ldots \ldots$ & $\ldots \ldots \ldots$ & $\ldots \ldots{ }^{--}$ & $\ldots-\ldots \ldots$ \\
\hline 10771 C. parvum & $--\ldots \ldots \ldots$ & $\ldots \ldots \ldots$ & $\ldots \ldots \ldots$ & $\ldots \ldots \ldots$ & $\ldots \ldots \ldots$ & $\ldots \ldots \ldots-$ & $\ldots-\ldots$ \\
\hline 10741 C. parvum-like & $--\ldots \ldots \ldots$ & $\ldots \ldots \ldots$ & $\ldots \ldots \ldots$ & $\ldots \ldots$ & $\ldots$ & $\ldots \ldots$ Tт & $\ldots$. \\
\hline 10748 C. parvum-like & --- & $\ldots \ldots \ldots$ & $\ldots \ldots \ldots$ & $\ldots \ldots \ldots$ & $\ldots \ldots \ldots$ & $\ldots \ldots$ тт. & $\ldots-\ldots$ \\
\hline C. ubiquitum MK573335 & -- A.... & . & $\cdots$ & $\ldots \ldots \ldots$ & $\cdots$ & $\ldots \ldots$-TA. & $\ldots-\ldots \ldots$ \\
\hline C. ubiquitum KY596694 & $--. \mathrm{A} . \ldots$ & . & $\cdots$ & $\cdots \ldots \ldots$ & $\cdots$ & $\ldots \ldots-T A$ & $\ldots-\ldots \ldots$ \\
\hline 11051 C. ubiquitum-like & TAA...... & ...G.... & $\cdots$ & $\ldots \ldots \ldots$ & $\cdots$ & ..G.G.TA. & ....... \\
\hline 11098 C. ubiquitum-like & TAA $\ldots \ldots$ & $\ldots$ G... & $\cdots$ & $\cdots \cdots$ & . & ..G.G.TA. & $\ldots$ т.... \\
\hline $\begin{array}{l}\text { C. suis MH8077493 } \\
5019 \text { C. occultus }\end{array}$ & $----\ldots$ & $\cdots \cdots \cdots$ & $\cdots \cdots \cdots$ & $\cdots \cdots \cdots$ & $\cdots \cdots \cdots$ & $\cdots \cdots-$-AT. & $\cdots-\ldots$ \\
\hline 5019 C. occultus & & & & & & & \\
\hline
\end{tabular}

the $S s p$ I and $V s p$ I restriction enzymes. The RFLP profile of $C$. occultus was similar to that of $C$. suis. Similarly, the C. ubiquitum-like genotype produced a RFLP profile similar to C. ubiquitum. In contrast, the banding pattern for the $C$. parvum-like genotype was different from $C$. parvum due to the presence of a $G$ to A substitution in the hypervariable region of the $S S U$ rRNA gene, leading to the creation of an additional $V s p$ I restriction site. This led to the cleavage of the upper VspI band in C. parvum into two smaller fragments (Fig. 3).

\section{Distribution of C. parvum, C. parvum-like and C. ubiquitum-like subtypes}

The 78 C. parvum, 45 C. parvum-like and 85 C. ubiquitum-like isolates were further subtyped by sequence analysis of the gp60 gene. Among them, 59 of the C. parvum, 30 of the C. parvum-like and 44 the C. ubiquitum-like isolates were successfully subtyped. Three subtypes of two rare subtype families were identified for $C$. parvum samples: IIpA9 ( $n=43)$; IIpA6 $(n=6)$; and IIoA15G1 $(n=9)$. One subtype each was identified for $C$. parvum-like and
C. ubiquitum-like genotypes (Fig. 2). The nucleotide sequences of IIpA9, IIpA6 and IIoA15G1 were identical to the GenBank reference sequence KC885904 obtained from bamboo rats, KC885904 obtained from bamboo rats and JN867335 obtained from humans, respectively $[6,23]$. The sequences from the C. parvum-like genotype were identical to each other and had a nucleotide identity of $87 \%$ to LC270810 obtained from camels [10]. Similarly, the sequences from the $C$. ubiquitum-like genotype had a nucleotide identity of $86 \%$ to KX698306 obtained from a water sample [24].

\section{Oocyst shedding intensity of Cryptosporidium spp.}

The intensity of oocyst shedding in infected bamboo rats was assessed using 18S-LC2 qPCR. The numbers of oocysts per gram of feces were 27,610 $\pm 71,911(n=27)$, $38,679 \pm 82,811(n=32), 2470 \pm 7017(n=37)$ and 1012 $(n=1)$ for $C$. parvum, $C$. parvum-like genotype, $C$. ubiquitum-like genotype and $C$. occultus, respectively (Table 1). 


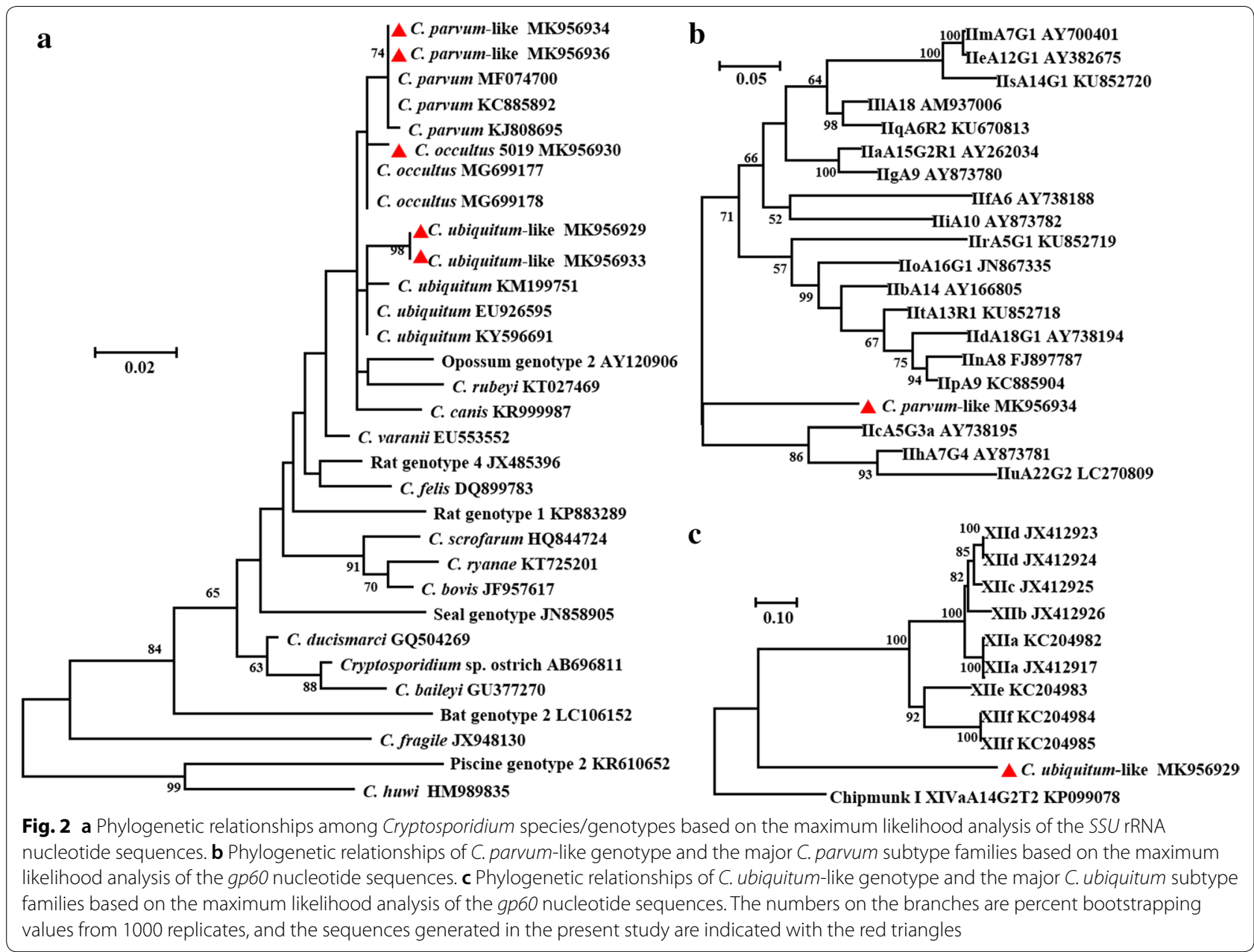

\section{Discussion}

Results of this study suggest that Cryptosporidium spp. are common in bamboo rats in Jiangxi, Guangxi and Hainan provinces, China. The overall detection rate of $29.5 \%$ for Cryptosporidium spp. is much higher than the $3.3 \%(3 / 92)$ in the only other study of cryptosporidiosis in bamboo rats conducted from a pet market in Sichuan Province [6]. The intensive nature of animal farming could have contributed to the high prevalence of Cryptosporidium spp. in bamboo rats in the present study. As often seen with cryptosporidiosis in other farmed animals, the detection rate was significantly higher in bamboo rats under two months of age $(70.0 \%)$ than those above 2 months (18.6\%). Among the nine farms, Cryptosporidium detection rates were higher on the two farms in Hainan, probably because of the sampling of only young animals on these farms. Farms 1 and 4 are leading breeders of bamboo rats in Guangxi. The large size of the farm and frequent animal trade could be responsible for the higher Cryptosporidium detection rates (24.3\% and $27.9 \%$, respectively) than on the other 4 farms
(5.6-11.1\%). The higher detection rate of Cryptosporidium spp. in breeding animals (13.1\%) than in other adults $(0-6.7 \%)$ could also be attributed to co-housing of animals from different cages.

Altogether, four Cryptosporidium species or genotypes were found in bamboo rats in this study. Of these, C. parvum has been detected in three bamboo rats previously [6]. The detection of C. occultus in one bamboo rat was also expected, as this species is mostly parasitizing rats to which bamboo rats are genetically related [25]. In addition to the two known Cryptosporidium species, we showed a common occurrence of two new Cryptosporidium genotypes in the studied animals, one genetically related to $C$. parvum and the other related to C. ubiquitum. Bamboo rats could be natural hosts of these two new Cryptosporidium genotypes, as indicated by their high occurrence in these animals.

The C. parvum-like and C. ubiquitum-like found in the present study appear to be genetically unique. Although C. parvum, C. ubiquitum-like and C. parvumlike were common in bamboo rats, $C$. parvum and the $C$. 

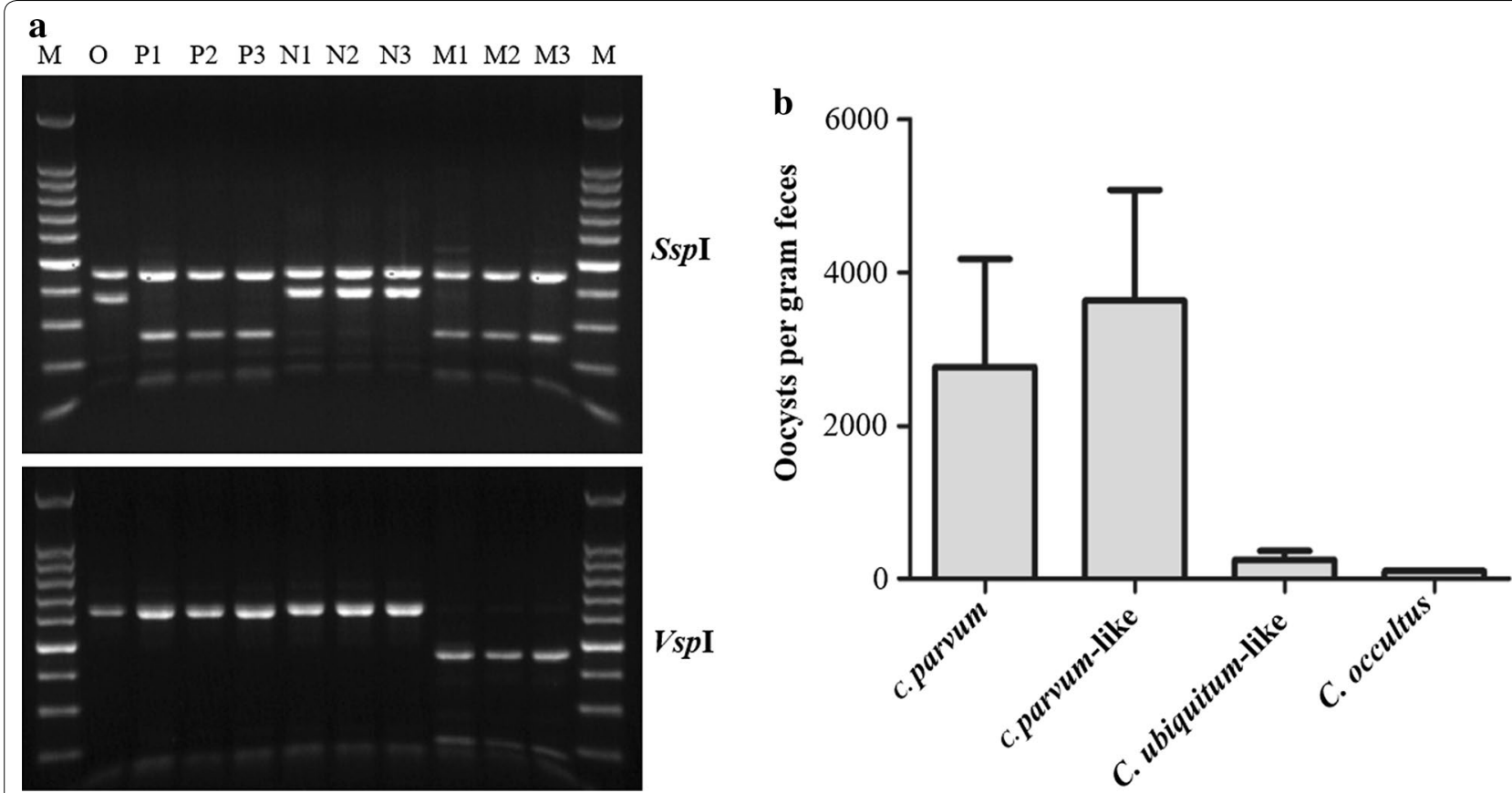

Fig. 3 a Patterns of restriction fragment length polymorphism analysis of the PCR products of the small subunit rRNA gene in Cryptosporidium spp. in bamboo rats. Upper panel: Sspl RFLP patterns; lower panel: Vspl RFLP patterns. Lane M: 100 bp molecular markers; Lane O: C. occultus; Lanes P1-P3: C. parvum; Lanes N1-N3: C. ubiquitum-like genotype; Lanes M1-M3: C. parvum-like genotype. b Oocyst shedding intensity of Cryptosporidium species and genotypes in bamboo rats as indicated by oocysts per gram of feces (mean \pm standard deviation)

parvum-like genotype were mainly detected in animals under two months of age, while the C. ubiquitum-like genotype was found in all age groups. In addition, C. parvum and the $C$. parvum-like genotype had much greater oocyst shedding intensity than the $C$. ubiquitum-like genotype. This observation is similar to the occurrence of C. parvum and C. ubiquitum in ruminants [2]. Further studies are needed to understand the host range of the new $C$. parvum-like and C. ubiquitum-like genotypes.

Cryptosporidium parvum found in bamboo rats in this study belongs to several rare subtypes. This is the most important zoonotic species with a broad host range, including ruminants, equine animals, rodents and primates [26]. However, genetic diversity and host adaptation are known to be present in C. parvum, with over 20 subtype families being described by sequence analysis of the gp60 gene [3]. The IIp subtype family detected in our study was previously reported from only in a few bamboo rats in China [6]. Similarly, the rare C. parvum IIo subtype family was first found in diarrheal patients with a history of travel to Thailand [23] and subsequently found in bamboo rats and crab-eating macaques in China $[6,7]$.

The public health significance of Cryptosporidium spp. in bamboo rats is not entirely clear. As mentioned above, the IIo subtype family of C. parvum found in the present study appears to be a minor human pathogen that has been found in only a few cryptosporidiosis cases [23]. However, it has recently been reported in 18 farmed crab-eating macaques in China [7]. Therefore, precaution should be taken to prevent the spread of this unique $C$. parvum subtype in farm animals. Similarly, although $C$. occultus has only been found in a few human cases [27], it appears to have a broad host range, including cattle, yak and Tanezumi rats [28-30]. As the new Cryptosporidium genotypes identified in this study are genetically related to C. parvum and C. ubiquitum, two well-known zoonotic Cryptosporidium species [3, 8], there is a need to examine their potential as causative agents of human infection.

\section{Conclusions}

Several Cryptosporidium species and genotypes, namely C. parvum, a C. parvum-like genotype, and a C. ubiquitum-like genotype, appear to be common in farmed bamboo rats in southern China. The C. parvum IIp and Ilo subtype families may have initially originated from native rodents, but have recently expanded to humans and non-human primates in China and Southeast Asia. Attention should be paid to monitoring the dispersal of these emerging C. parvum subtypes in farm animals. 


\section{Abbreviations}

PCR: polymerase chain reaction; qPCR: a quantitative PCR; gp60: 60 kDa glycoprotein gene; SSU rRNA: the small subunit rRNA; RFLP: restriction fragment length polymorphism.

\section{Acknowledgements}

We thank the farm owners for the assistance in sample collection from bamboo rats.

\section{Authors' contributions}

YF and LX conceived and designed the experiments. FL and ZZ and SH performed the experiments. FL, ZZ, SH, WZ, JZ, MK, YG and NL analyzed the data. FL, YF and LX wrote the paper. All authors read and approved the final manuscript.

\section{Funding}

This study was supported by the National Natural Science Foundation of China (31820103014 and 31630078), and the 111 Project (D20008).

\section{Availability of data and materials}

Data supporting the conclusions of this article are included within the article. Representative nucleotide sequences generated in the study were submitted to the GenBank database under the accession numbers MK956928-MK956937، MK955996-MK956002, MT019967 and MT019968.

\section{Ethics approval and consent to participate}

The fecal samples used in the study were collected from bamboo rats with the permission of the farm owners. Fecal pellets on the pen floor were collected without any handling of the animals. The study was approved by the Research Ethics Committee of the South China Agricultural University.

\section{Consent for publication}

Not applicable.

\section{Competing interests}

The authors declare that they have no competing interests.

\section{Author details}

${ }^{1}$ Key Laboratory of Zoonosis of Ministry of Agriculture, College of Veterinary Medicine, South China Agricultural University, Guangzhou 510642, Guangdong, China. ${ }^{2}$ Guangdong Laboratory for Lingnan Modern Agriculture, Guangzhou 510642, Guangdong, China. ${ }^{3}$ Key Laboratory of Tropical Biological Resources of Ministry of Education, School of Life and Pharmaceutical Sciences, Hainan University, Haikou 570228, Hainan, China. ${ }^{4}$ Institute of Parasitology, Biology Centre of the Czech Academy of Sciences, 37005 Ceske Budejovice, Czech Republic.

Received: 3 August 2019 Accepted: 16 March 2020

Published online: 24 March 2020

\section{References}

1. Fayer R. Taxonomy and species delimitation in Cryptosporidium. Exp Parasitol. 2010;124:90-7.

2. Xiao L. Molecular epidemiology of cryptosporidiosis: an update. Exp Parasitol. 2010;124:80-9.

3. Feng Y, Ryan UM, Xiao L. Genetic diversity and population structure of Cryptosporidium. Trends Parasitol. 2018;34:997-1011.

4. Santin M. Clinical and subclinical infections with Cryptosporidium in animals. N Z Vet J. 2013;61:1-10.

5. Feng Y, Xiao L. Molecular epidemiology of cryptosporidiosis in China. Front Microbiol. 2017:8:1701

6. Liu X, Zhou X, Zhong Z, Zuo Z, Shi J, Wang Y, et al. Occurrence of novel and rare subtype families of Cryptosporidium in bamboo rats (Rhizomys sinensis) in China. Vet Parasitol. 2015;207:144-8

7. Chen L, Hu S, Jiang W, Zhao J, Li N, Guo Y, et al. Cryptosporidium parvum and Cryptosporidium hominis subtypes in crab-eating macaques. Parasit Vectors. 2019;12:350.

8. Li N, Xiao L, Alderisio K, Elwin K, Cebelinski E, Chalmers R, et al. Subtyping Cryptosporidium ubiquitum, a zoonotic pathogen emerging in humans. Emerg Infect Dis. 2014;20:217-24.
9. Tang HB, Chen F, Rao G, Bai A, Jiang J, Du Y, et al. Characterization of Akabane virus from domestic bamboo rat, southern China. Vet Microbiol. 2017:207:280-5.

10. Liu J, Tang CH, Zhou DC, Zeng QB. Current situation and countermeasures of bamboo rat in China. J Hunan Environ-Biolog Polytechnic. 2011;17:1-5.

11. Cao C, Liang L, Wang W, Luo H, Huang S, Liu D, et al. Common reservoirs for Penicillium marneffei infection in humans and rodents, China. Emerg Infect Dis. 2011;17:209-14.

12. Huang $X, \mathrm{He} G$, Lu S, Liang $Y, X i$ L. Role of Rhizomys pruinosus as a natural animal host of Penicillium marneffei in Guangdong, China. Microb Biotechnol. 2015;8:659-64.

13. Ma X, Wang Y, Zhang HJ, Wu HX, Zhao GH. First report of Giardia duodenalis infection in bamboo rats. Parasit Vectors. 2018;11:520.

14. Wang H, Liu Q, Jiang X, Zhang Y, Zhao A, Cui Z, et al. Dominance of zoonotic genotype $D$ of Enterocytozoon bieneusi in bamboo rats (Rhizomys sinensis). Infect Gene Evol. 2019;73:113-8.

15. Zhang H, Li K, Wang Y, Rehman MU, Liu Y, Jin J, et al. Investigation and characterization of beta-lactam resistance in Escherichia coli strains isolated from bamboo rats (Rhizomys sinensis) in Zhejiang province, China. J Vet Med Sci. 2017:79:1633-6.

16. Jiang J, Alderisio KA, Singh A, Xiao L. Development of procedures for direct extraction of Cryptosporidium DNA from water concentrates and for relief of PCR inhibitors. Appl Environ Microbiol. 2005;71:1135-41.

17. Xiao L, Morgan UM, Limor J, Escalante A, Arrowood M, Shulaw W, et al. Genetic diversity within Cryptosporidium parvum and related Cryptosporidium species. Appl Environ Microbiol. 1999;65:3386-91.

18. Alves M, Xiao L, Sulaiman I, Lal AA, Matos O, Antunes F. Subgenotype analysis of Cryptosporidium isolates from humans, cattle, and zoo ruminants in Portugal. J Clin Microbiol. 2003:41:2744-7.

19. Guo Y, Cebelinski E, Matusevich C, Alderisio KA, Lebbad M, McEvoy J, et al. Subtyping novel zoonotic pathogen Cryptosporidium chipmunk genotype I. J Clin Microbiol. 2015;53:1648-54.

20. Li N, Neumann NF, Ruecker N, Alderisio KA, Sturbaum GD, Villegas EN, et al. Development and evaluation of three real-time PCR assays for genotyping and source tracking Cryptosporidium spp. in water. Appl Environ Microbiol. 2015:81:5845-54.

21. Kellnerova K, Holubova N, Jandova A, Vejcik A, McEvoy J, Sak B, et al. First description of Cryptosporidium ubiquitum Xlla subtype family in farmed fur animals. Eur J Protistol. 2017;59:108-13.

22. Cai M, Guo Y, Pan B, Li N, Wang X, Tang C, et al. Longitudinal monitoring of Cryptosporidium species in pre-weaned dairy calves on five farms in Shanghai, China. Vet Parasitol. 2017:241:14-9.

23. Insulander M, Silverlas C, Lebbad M, Karlsson L, Mattsson JG, Svenungsson B. Molecular epidemiology and clinical manifestations of human cryptosporidiosis in Sweden. Epidemiol Infect. 2013;141:1009-20.

24. Yan W, Alderisio K, Roellig DM, Elwin K, Chalmers RM, et al. Subtype analysis of zoonotic pathogen Cryptosporidium skunk genotype. Infect Genet Evol. 2017:55:20-5.

25. Kvac M, VInata G, Jezkova J, Horcickova M, Konecny R, Hlaskova L, et al. Cryptosporidium occultus sp. n. (Apicomplexa: Cryptosporidiidae) in rats. Eur J Protistol. 2018:63:96-104.

26. Ryan U, Fayer R, Xiao L. Cryptosporidium species in humans and animals: current understanding and research needs. Parasitology. 2014;141:1667-85.

27. Ong CS, Eisler DL, Alikhani A, Fung WW, Tomblin J, Bowie WR, et al. Novel Cryptosporidium genotypes in sporadic cryptosporidiosis cases: first report of human infections with a cervine genotype. Emerg Infect Dis. 2002;8:263-8.

28. Langkjaer RB, Vigre H, Enemark HL, Maddox-Hyttel C. Molecular and phylogenetic characterization of Cryptosporidium and Giardia from pigs and cattle in Denmark. Parasitology. 2007:134:339-50.

29. Ng-Hublin JS, Singleton GR, Ryan U. Molecular characterization of Cryptosporidium spp. from wild rats and mice from rural communities in the Philippines. Infect Genet Evol. 2013;16:5-12.

30. Li P, Cai J, Cai M, Wu W, Li C, Lei M, et al. Distribution of Cryptosporidium species in Tibetan sheep and yaks in Qinghai, China. Vet Parasitol. 2016;215:58-62.

\section{Publisher's Note}

Springer Nature remains neutral with regard to jurisdictional claims in published maps and institutional affiliations. 